\title{
The role of calcium sensor-interacting protein kinases in plant adaptation to potassium-deficiency: new answers to old questions
}

\author{
Anna Amtmann ${ }^{1}$, Patrick Armengaud ${ }^{1}$ \\ ${ }^{1}$ Plant Sciences Group, Institute of Biomedical and Life Sciences, University of Glasgow, Glasgow G12 8QQ, UK. a.amtmann@bio. \\ gla.ac.uk
}

Cell Research (2007) 17:483-485. doi: 10.1038/cr.2007.49; published online 14 Jun 2007

Potassium $\left(\mathrm{K}^{+}\right)$is an essential macronutrient for all living organisms and large amounts are required for plant growth and development. In many regions of $\mathrm{Asia}^{+}$-fertilization has been neglected and soils have become $\mathrm{K}^{+}$-depleted. $\mathrm{K}^{+}$deficiency in the field diminishes not only crop production but also leads to environmental problems due to inefficient usage and leaching of nitrate. Consequences of $\mathrm{K}^{+}$-deficiency on crop production range from decreased biomass, nutritional quality and taste of the crops to inferior harvest and storage properties, as well as increased susceptibility to disease. Effects of $\mathrm{K}^{+}$-deficiency on plant physiology include decreased photosynthetic rate, impaired tissue allocation of sugars and amino acids, decreased protein synthesis, and lack of control over turgor and gas exchange [1]. $\mathrm{K}^{+}$uptake and its re-distribution within the plant is facilitated by a plethora of membrane transport proteins displaying an astonishing diversity with respect to their affinity and selectivity for $\mathrm{K}^{+}$, mode and direction of transport, tissue specific expression, membrane localization and regulation [2]. Microarray experiments have shown that - in contrast to transporters of other macronutrients - genes encoding $\mathrm{K}^{+}$-transporters display surprisingly little responsiveness to the external nutrient supply [3]. This observation probably reflects that because of its vital role in maintenance of cell turgor and membrane potential $\mathrm{K}^{+}$-transport has to respond very quickly to changes in the environment. Hence, posttranslational control mechanisms are required.

Two recent studies have provided exciting new information on this issue. $\mathrm{Wu}$ and colleagues [4] and Luan and colleagues [5] identified a calcineurin B-like protein (CBL)-interacting protein kinase CIPK23 and two upstream elements, CBL1 and CBL9, as regulators of AKT1. AKT1 is a Shaker-type voltage-gated ion channel that mediates the uptake of $\mathrm{K}^{+}$at hyperpolarized membrane voltages [2]. The importance of AKT1 for $\mathrm{K}^{+}$-uptake from the root environment had previously been proven in Arabidopsis akt 1 knock-out mutants, which show impaired growth in low external $\mathrm{K}^{+}$-concentrations, when high-affinity $\mathrm{K}^{+}$-transporters are inhibited by ammonium [6]. The CIPK/CBL regulatory system links $\mathrm{K}^{+}$-uptake to cytoplasmic $\mathrm{Ca}^{2+}$, the most important secondary messenger in plants, and is thus reminiscent of the SOS signalling pathway, which controls cellular $\mathrm{Na}^{+}$-homeostasis [2].

The paper by Pandey et al. in a recent issue of Cell Research [7] identifies another member of the CIPK family, CIPK9, as playing an important role in plant adaptation to $\mathrm{K}^{+}$-deficiency. The authors report that two independent Arabidopsis T-DNA insertion knock-out lines for CIPK9 show impaired growth under conditions of low $\mathrm{K}^{+}$-supply. The response is specific for $\mathrm{K}^{+}$as the phenotype is caused by depletion of the growth medium for $\mathrm{K}^{+}$but not for other ions. However, in contrast to the phenotype caused by knock-out of CIPK23, root and shoot total tissue $\mathrm{K}^{+}$contents were unchanged in cipk 9 mutants compared to wildtype.

The study raises the question which processes other than $\mathrm{K}^{+}$acquisition are important for plant growth in $\mathrm{K}^{+}$deficient conditions. One possibility is that CIPK9, as CIPK23, interacts with a $\mathrm{K}^{+}$-channel, but that unlike AKT1 this channel does not reside in the root plasma membrane. Experiments with $\mathrm{K}^{+}$-selective microelectrodes have shown that under varying extracellular $\mathrm{K}^{+}$-concentrations cytoplasmic $\mathrm{K}^{+}$-concentrations in root cells are maintained at a constant level at the cost of vacuolar $\mathrm{K}^{+}[8]$. Thus, the 
vacuolar $\mathrm{K}^{+}$-pool is used as a flexible store for cellular $\mathrm{K}^{+}$-homeostasis. Several $\mathrm{K}^{+}$-permeable channels in the tonoplast could facilitate $\mathrm{K}^{+}$release from the vacuole under $\mathrm{K}^{+}$-deficient conditions [2] but the question how these channels 'sense' the external $\mathrm{K}^{+}$-concentrations has long puzzled researchers in the field. The possibility that CIPK9 directly regulates a vacuolar $\mathrm{K}^{+}$-channel thereby linking channel gating to external $\mathrm{K}^{+}$via a cytoplasmic $\mathrm{Ca}^{2+}$ signal is therefore intriguing. $\mathrm{K}^{+}$-homeostasis operates not only at the cellular level but also at the tissue level. This is apparent in the fact that $\mathrm{K}^{+}$-deficiency symptoms appear first in older leaves. Effective re-location of $\mathrm{K}^{+}$from older into younger leaves requires regulation of plasma membrane and tonoplast $\mathrm{K}^{+}$-transporters in a number of different cell types, and CIPK9 could be an essential component of this regulatory network.

Another possibility is that CIPK9 regulation targets aspects of plant adaptation to low $\mathrm{K}^{+}$that are not linked to $\mathrm{K}^{+}$-transport. Although cellular and tissue $\mathrm{K}^{+}$-homeostasis can protect metabolically active cells from serious $\mathrm{K}^{+}$-deficiency for a limited period of time, it is clear that a plant that experiences long-term $\mathrm{K}^{+}$-deficiency will have to re-prioritise its growth, development and metabolism to achieve maximal seed production with limited resources. Research in our lab has identified jasmonic acid (JA) as a potential central integrator of the adaptation process [9]. Microarray analysis showed that a large percentage of the
$\mathrm{K}^{+}$-responsive transcriptome is related to JA, and a rise of JA during $\mathrm{K}^{+}$-deficiency, as well as the specificity of this response for $\mathrm{K}^{+}$-deficiency, have since been confirmed [A Amtmann, P Armengaud, unpublished data]. JA is well known to play a role in growth inhibition, senescence and stomatal closure; processes that are crucial for plant adaptation to $\mathrm{K}^{+}$-deficiency. Our microarray study also identified CIPK 9 as being transcriptionally regulated by $\mathrm{K}^{+}$, and subsequent profiling of the $\mathrm{K}^{+}$-responsive transcriptome in JA-signalling mutants showed that CIPK9 regulation is independent of JA-signalling. In the light of these findings it is exciting that Pandey et al. [7] report enhanced expression of CIPK9 after wounding, another well-known stimulus for JA biosynthesis. CIPK9 could therefore be an essential upstream component of JA-mediated adaptive responses to $\mathrm{K}^{+}$-deficiency.

A number of experiments are now required to further characterize the physiological role of CIPK9. Yeast twohybrid assays should be carried out to identify both upstream (e.g. CBLs) and downstream (e.g. $\mathrm{K}^{+}$-transporters) interactors of CIPK9. To test the possibility that CIPK9 is involved in more general aspects of plant adaptation to low $\mathrm{K}^{+}$cipk9 mutants should be subjected to microarray analysis and the transcriptional profile compared with available data from wildtype plants. To position CIPK9 within the $\mathrm{K}^{+}$-signalling network, dependence of its transcriptional $\mathrm{K}^{+}$-responsiveness to a putative ROS-upstream signal [10],

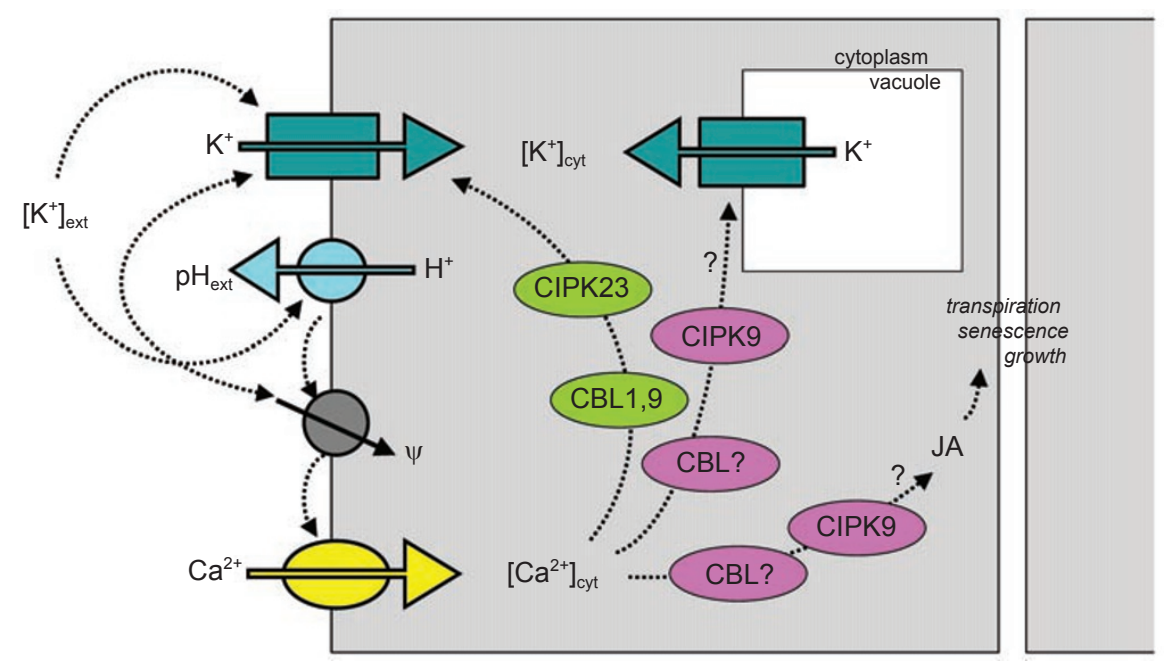

Figure 1 Putative functions of CBL/CIPK pathways in $\mathrm{K}^{+}$-signalling. Through its effect on plasma membrane $\mathrm{K}^{+}$- and $\mathrm{H}^{+}$-conductance a decrease in external $\mathrm{K}^{+}$leads to membrane hyperpolarisation and subsequent activation of voltage-dependent $\mathrm{Ca}^{2+}$-channels. Calcineurin B-like sensor proteins (CBLs) detect the rise in cytoplasmic $\mathrm{Ca}^{2+}$ and activate $\mathrm{CBL}$-interacting protein kinases (CIPKs). Possible targets of CIPK regulation are plasma membrane $\mathrm{K}^{+}$-channels facilitating $\mathrm{K}^{+}$-uptake from the external medium, tonoplast $\mathrm{K}^{+}$-channels mediating $\mathrm{K}^{+}$-release from the vacuole, and upstream elements of hormonal pathways integrating a range of physiological adaptations. 
and its requirement for a JA-downstream signal should be evaluated.

The recent discovery of the CIPK/CBL regulatory system has made a major contribution to our knowledge of how plants perceive external $\mathrm{K}^{+}$(Figure 1), a question that has occupied researchers for some 50 years. Future studies should aim to explore the function of this system in a wholeplant context, thus enhancing systemic understanding of a phenomenon that is not only of great scientific interest but also of central importance for sustainable agriculture worldwide.

\section{References}

1 Marschner H, ed. Mineral nutrition of higher plants. 2nd edition. London: Academic Press, 1995.

2 Amtmann A, Armengaud P, Volkov V. Potassium nutrition and salt stress. In: Blatt MR, ed. Membrane Transport in Plants. Oxford: Blackwell Publishing 2004; 293-339.

3 Maathuis FJM, Filatov V, Herzyk P, et al. Transcriptome analysis of root transporters reveals participation of multiple gene families in the response to cation stress. Plant J 2003; 35:675-692.
$4 \mathrm{Xu}$ J, Li HD, Chen LQ, et al. A protein kinase, interacting with two calcineurin B-like proteins, regulates $\mathrm{K}^{+}$transporter AKT1 in Arabidopsis. Cell 2006; 125:1347-1360.

5 Li L, Kim BG, Cheong YH, Pandey GK, Luan S. A Ca ${ }^{2+}$ signaling pathway regulates a $\mathrm{K}^{+}$channel for low-K response in Arabidopsis. Proc Natl Acad Sci USA 2006; 103:12625-12630.

6 Hirsch RE, Lewis BD, Spalding EP, Sussman MR. A role for the AKT1 potassium channel in plant nutrition. Science 1998; 280:918-921.

7 Pandey GK, Cheong YH, Kim BG, Grant JJ, Li L, Luan S. CIPK9, a calcium sensor-interacting protein kinase required for low-potassium tolerance in Arabidopsis. Cell Res 2007; 17:411421.

8 Walker DJ, Leigh RA, Miller AJ. Potassium homeostasis in vacuolate plant cells. Proc Natl Acad Sci USA 1996; 93:1051010514.

9 Armengaud P, Breitling R, Amtmann A. The potassium-dependent transcriptome of Arabidopsis reveals a prominent role of jasmonic acid in nutrient signalling. Plant Physiol 2004; 136:2556-2576.

10 Shin R, Schachtman DP. Hydrogen peroxide mediates plant root cell response to nutrient deprivation. Proc Natl Acad Sci USA 2004; 101:8827-8832. 